\title{
O PEJORATIVO “LEPRA” E A GRANDE VÍTIMA DE GRAVE ERRO MÉDICO-SOCIAL-HISTÓRICO:
} A INDEFESA AMERICA LATINA.

\author{
ABRAHÃO ROTBERG \\ da Divisão de Hansenologia e Dermatologia Sanitária \\ do Instituto de Saúde (Secretaria da Saúde, S. P.).
}

Contrariamente ao que supõe a maioria, a hanseníase ("lepra") não é "moléstia bíblica". Nenhum de seus sinais característicos figura no Velho Testamento. O "tsara'ath" dos livros sagrados hebreus significava degradação moral (e/ou sagrada-ritual), motivada por série confusa e variada de alterações da pele e couro cabeludo que poderiam corresponder hoje, mais propriamente, às parasitoses, piodermites, psoríase, vitiligo e pênfigos $(3,5,9,21)$. Seu portador era declarado "imundo" pelo Sacerdote e expulso para "fora do acampamento", enquanto que roupas e paredes com "tsara'ath", provavelmente apenas mofadas, eram queimadas ou destruidas, carregando-se as pedras e restos para um "lugar imundo".

Por iniciativa de Ptolomeu II, o Filadelfo, a Torá, os Neviim e os Ketuvim hebraicos foram traduzidos para o grego, no século III a. C. e transformaram-se na Bíblia. Ao depararem com o "tsara'ath", os 70 ou 72 letrados judeus encarregados da tarefa, não acharam nada melhor que "lepra", palavra grega significando descamação e exfoliação (do mesmo radical de 'livro'), a qual, possivelmente, nessa fase da vida helênica, teria conotação de "impureza" ou "desonra" - algo semelhante, talvez, à "casca grossa" brasileira. Tambem não se tratava de hanseníase, já que esta era conhecida pelos povos mediterrâneos da época sob outros nomes, "elefantíase" entre os gregos.

O termo "lepra" dessa Septuaginta foi conservado sem alteração na Vulgata, a tradução latina de São Jerônimo, propagando-se assim, para todo o Império Romano e o novo e crescente mundo cristão, a antiga degradação do hebraico "tsara'ath". Tal propagação acabou envolvendo a própria "elefantíase", isto é, a hanseníase, não referida no texto hebraico original. Mais tarde, a "lepra alphos" tornar-se-ia 
"psoríase" e todas as demais "lepras" da Septuaginta e da Vulgata viriam a se transformar, no decurso dos séculos, em "micoses", "pênfigos", "vitiligo", "eczemas" e outras novas designações mais compatíveis com o lento progresso da medicina - com uma única exceção: a recem-chegada "lepra", desconhecida dos antigos hebreus (fig. 1).

Conclusão curiosa, que seria apenas comica se suas consequências não tivessem sido tão trágicas para os milhões de enfermos e seus familiares no mundo cristão e tão desesperadoras para todos os responsáveis pelo esclarecimento do público e prevenção da moléstia: enquanto que, graças a seus novos nomes, as antigas "lepras biblicas" escapavam gradativamente da estigmatização social, a "lepra" atual, não referida no Velho Testamento, é que veio a herdar toda a maldição do "tsara"ath".

Ao bacilo descoberto por Hansen, em 1873, não conferiram os bacteriologistas um merecido gênero "Hansenia", nem mesmo, uma simples espécie "hansenii"; lançaram-the todo o peso da espécie "leprae" e transformaram-na na micobactéria da infâmia e da rejeição. Consolidavam-se a herança espúria e o ostracismo social.

\section{Os protestos inúteis.}

Não faltaram protestos em todo o mundo cristão contra esse erro histórico e inominavel injustiça. Médicos, literatos, humanistas, educadores e os próprios enfermos, há mais de meio século, protestam energicamente contra essa "lepra" desmoralizante. Nada mais conseguiram que tímida e habitualmente desobedecida recomendação internacional contra o uso do termo "leproso". Cinquenta e quatro anos após a primeira recomendação da Conferência de Manila (1931), ratificada pelos Congressos Internacionais de Havana (1948) e Madrid (1953), os "leprosos", ou seja, os "sujos" e "repelentes" dos dicionários e da boca do povo, continuam tão vivos como nunca, inclusive em artigos médicos e mesmo em publicações de organismos internacionais responsáveis.

Há mais de 30 anos vem o Star, revista bimestral dos poucos mas organizados enfermos norte-americanos, defendendo o termo "Hansen's disease" e lutando contra a discriminação e humilhação que os tortura e contra o terror que o termo "lepra" implanta. Entretanto, nada conseguiram dos leprólogos (terminologia corrente) que, pelo visto, constituem o único grupamento humano que adota o lema de 


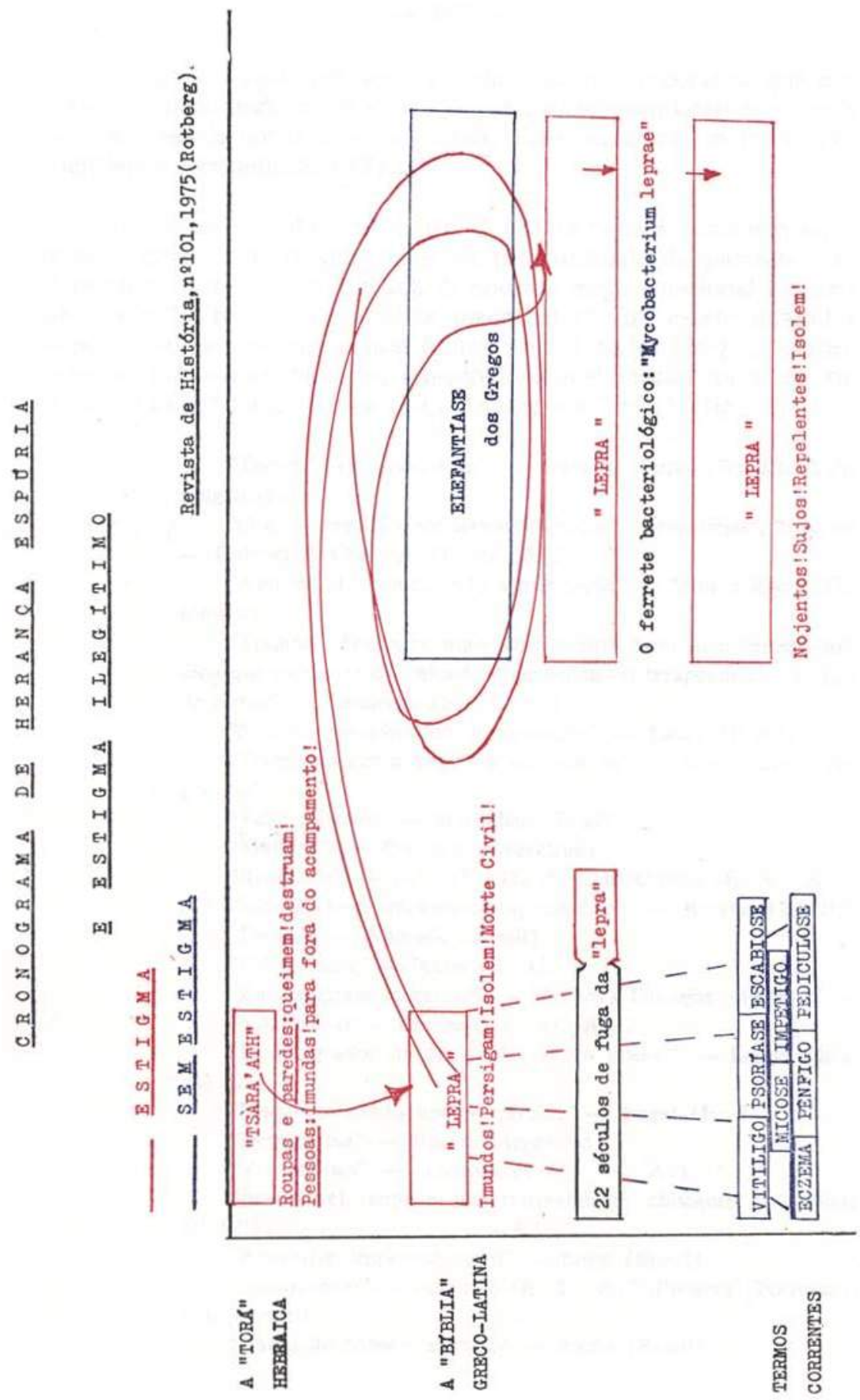


que "o freguês nunca tem razão", paradoxalmente esperando que este "freguês", humilhado e ofendido, coopere; e surpreendendo-se quando ele, temeroso de novas estigmatizações, não comparece aos centros de diagnóstico e tratamento (17).

Investigações realizadas no Brasil (8) já tinham concluido ser o termo "lepra", um "desintegrador da personalidade do paciente"; na Argentina (10), palavra "dotada de enorme carga emocional negativa de repulsa", "rótulo que penetra precocemente na mente infantil e impede qualquer esclarecimento futuro"; nos Estados Unidos, "o mais negativo dos termos médicos, impedindo a reabilitação social do enfermo" (14), "dor e trauma psíquico contínuo" (12) (fig. 2).

"Temivel, estigmatizante" — Rabello, Pupo (Brasil); Vella (Inglaterra)

"O mais negativo dos termos médicos", "prejudicial", "nocivo"

- Rolston \& Chesteen (E. U. A.).

"Anti-social, prejudicando a prevenção" - Muñoz Rivas (Colômbia).

"Trágico", "barreira mais séria contra bom atendimento médico que qualquer dificuldade diagnóstica ou terapêutica", "cortina de terror" - Lendrum (E. U. A.) .

"Nocivo, prejudicando a prevenção" - Lacaz (Brasil). gentina) .

"Tremenda carga negativa de rejeição" - Mangiaterra (Ar-

"Tabú milenar" - Maranhão (Brasil) .

"Maligno" - Quiroga (Argentina).

"Repelente" - Dow (E. U. A.); Blochman (E. U. A.).

"Supersticioso, milenarmente maldito" - Becker (Brasil).

"Pesado" - Andrade (Brasil).

"Ostracizante" - Reiss (E. U. A.).

"Enormemente negativo" - Montoya Obregon (Perú).

"Vil, odioso" - Burgess (E. U. A.).

"Desintegrador da personalidade do doente" - Letayf (Brasil).

"Feio, lembrando horror, pecado" - Faget (E. U. A.).

"Deprimente" - Borda (Argentina).

"Vergonhoso" - Lichtwardt (E. U. A.) .

"Inaceitavel, deprimente, terrivelmente chocante" - Diniz (Brasil).

"Pejorativo impronunciavel" - Bopp (Brasil) .

"Ignominioso" - Feldman (E. U. A.); Fonseca (Portugal);

Cini (Brasil) .

"Causa de crime e suicídio" - Souza (Brasil). 


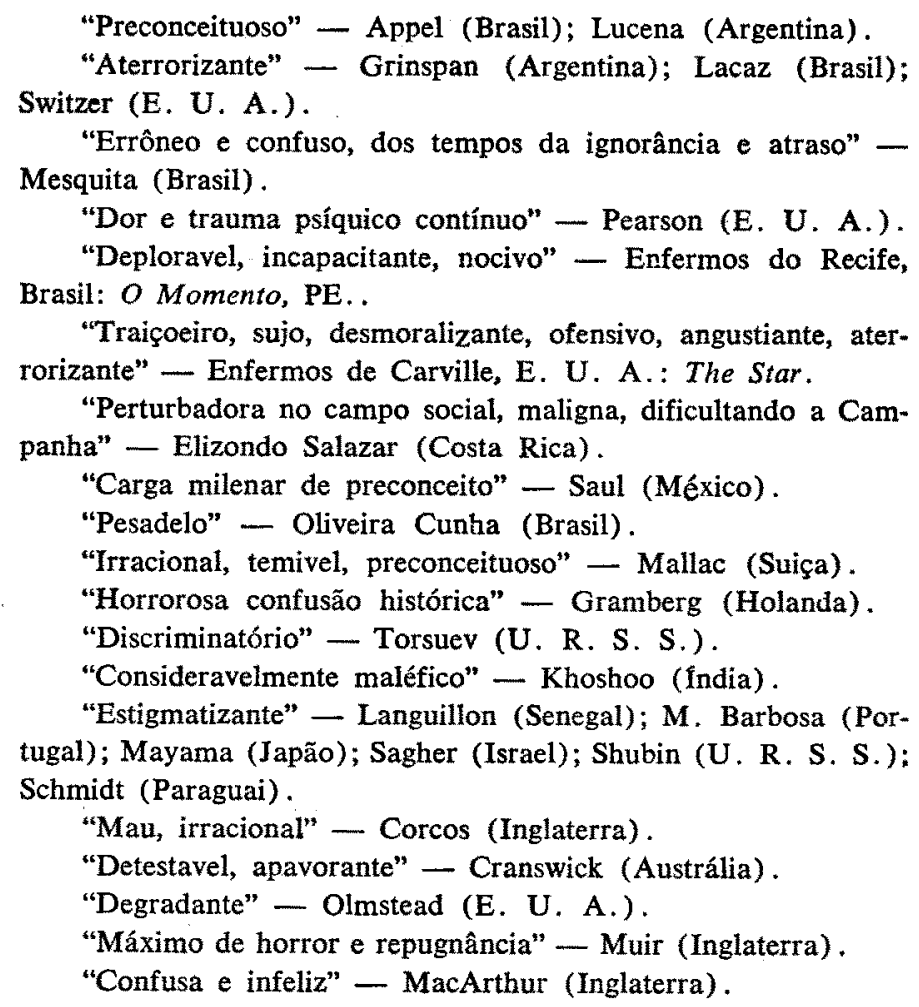

Fig. 2. - Algumas opiniōes sobre o pejorativo "lepra".

Fugindo ao terror inerente ao termo "lepra" e seus derivados, dispensários "anti-leprosos", bem como campanhas contra a "lepra", transformaram-se no México, Venezuela e Argentina em "Centros Dermatológicos", "Dermatologia Sanitária" e "Lucha Dermatológica", respectivamente.

Em 1967, comprovado o total insucesso de décadas de tentativas de esclarecer o público sobre a "lepra" - sempre abortadas pelo intenso e permanente sensacionalismo anti-educativo ligado ao termo - a Secretaria da Saude do Estado de São Paulo adotou experimentalmente o neologismo "hanseníase", oficializado em 1970 (7), de acordo, aliás, com a recomendação de ponderavel (42\%) Grupo de Participantes de Seminário promovido pela Organização Panamericana de Saude (1968) - Semináric que, unanimemente, reconhecera a falência da educação sobre "lepra" nas Américas; e com as conclusões 


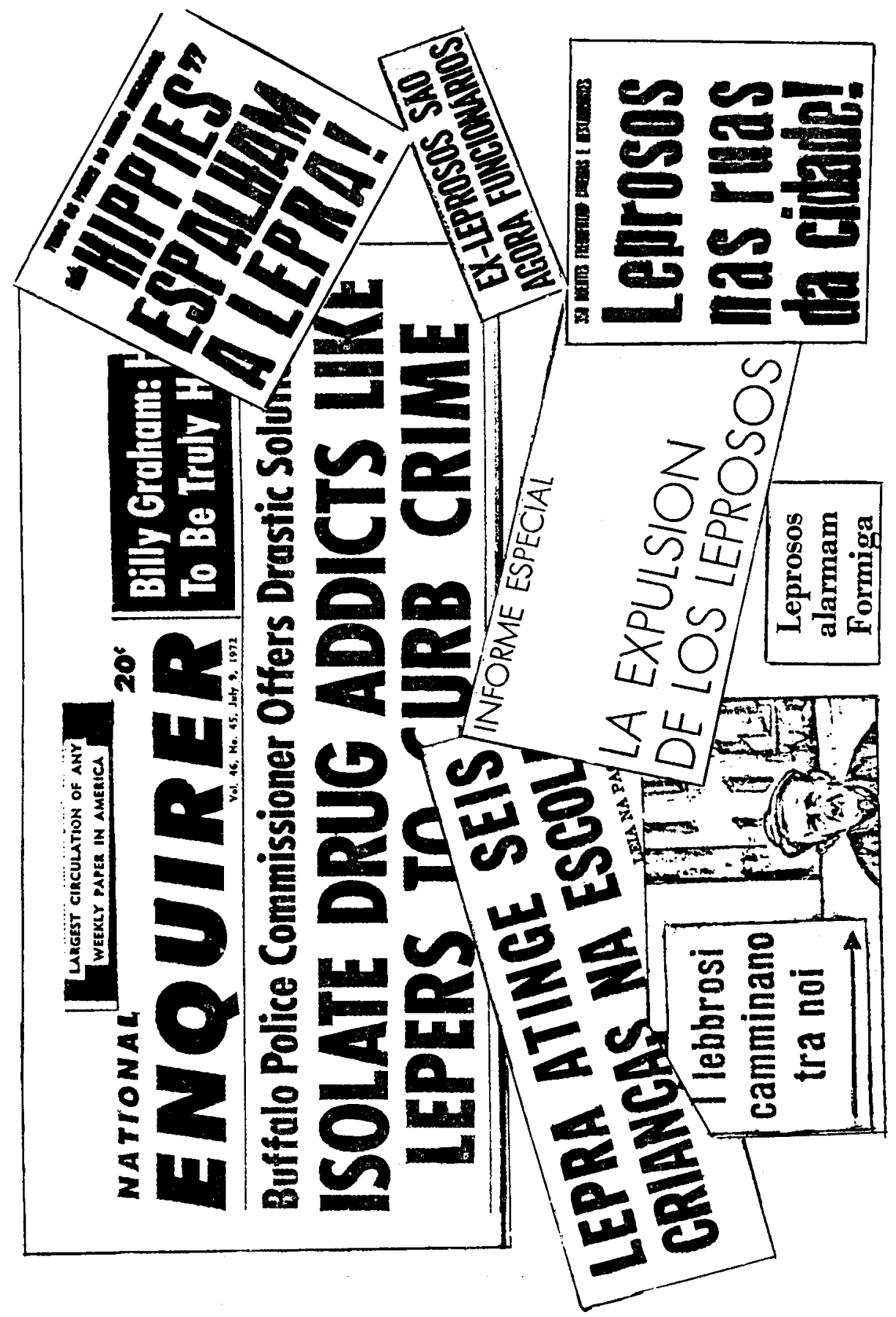

Fig. 3. - Anti-educação com "lepra": permanente, poderosa, invencivel. 
de dois Congressos Brasileiros de Higiene (Salvador, 1968, São Paulo, 1970). Que era desejada nova orientação educativa, livre dos preconceitos indissoluvelmente ligados à temerosa "lepra", atestam a franca aceitação da nova terminologia pela Nomenclatura Dermatológica (13), pela Nômina Dermatológica (2), pelos Governos de 6 outros Estados brasileiros (Amazonas, Ceará, Espírito Santo, Paraiba, Paraná e Piauí), por mais de 40 escolas médicas em doze estados e por grande número de escritores e jornalistas, médicos ou não, no Brasil e exterior, principalmente Portugal, Argentina e Estados Unidos.

Os verdadeiros motivos da conservação do pejorativo "lepra": a indiferença pelos problemas da minoria e o valor financeiro do termo.

Surpreendentemente, nenhum desses fatos despertou o interesse das entidades internacionais e mesmo um apelo de signatários de 15 países ao 'X Congresso Internacional de Lepra' (Bergen, 1973), simplesmente para que se "estudasse a possibilidade" de nova terminologia, foi rejeitado (11).

Anteriormente, dois artigos mostrando os primeiros indícios favoráveis da experiência de São Paulo (15) e apelando para a cooperação mundial (16), haviam provocado numerosas adesões e manifestações de interesse, mas tambem objeçōes mal-fundamentadas e contraditórias, em geral semelhantes às levantadas no passado contra os antigos e irrefutáveis argumentos de outros autores e do Star. Exemplos: a). - "A educação é que vai tornar a "lepra" aceitavel" Falso: nenhuma tentativa educativa vencerá a antiga, permanente e poderosa anti-educação com "lepra" por todos os meios de comunicação (fig. 3); b). - "Qualquer nome novo vai herdar a malignidade da "lepra" " - Falso: milhares de nomes, médicos ou não, vêm se modificando, em cada um dos múltiplos ramos da atividade humana e raros se recordam dos antigos: a "lepra" não será exceção; c). "hanseníase" é eponímico, lexicamente irregular" - De acordo: dêm-nos termo melhor (que até hoje não surgiu). Note-se ainda a contradição entre os itens a) e b).

Finalmente, começaram a aparecer os motivos sérios (e dificilmente removíveis) da conservação do pejorativo "lepra":

1. - A indiferença da maioria pelos problemas da minoria das Américas $e$ de alguns paises européus.

Por declarações verbais, cartas e publicaçōes afirmam vários autores que $o$ termo "lepra" $s \delta$ ofende e prejudica os enfermos 
das Américas, que são minoria; cerca de $97 \%$ dos enfermos vivem na Äfrica. Ásia e Oceania e não são vitimados pelo pejorativo greco-latino. O que não se entende, e se estranha, é o por que dessa objeção feita pela maioria, contra modificação terminológica das línguas anglo-latinas (que essa mesma maioria não utiliza) que seria favoravel aos $3 \%$ restantes.

A publicação mais recente e característica nesse sentido admite, "talvez", as dificuldades brasileiras, mas "estranha esse esforço para alterar costume mundial, com a finalidade de promover modificação social e cultural no Brasil" (19). Para ser preciso, nem se trata de "costume mundial", mas apenas anglo-latino, nem o Brasil é a única vítima.

Na realidade, não é a maioria afro-oriental que objeta ativamente, mas sim a minoria de autores influentes de áreas não-endêmicas e de língua anglo-latina, pouco dispostos a trabalhar para eliminar os termos "leprosy" e "lèpre", que não injuriam seus concidadãos da América do Norte e Europa nem prejudicam seus inexistentes, por desnecessários, serviços preventivos.

2. - O sensacionalistico termo "lepra" como insubstituivel fonte de renda:

Para poder angariar donativos visando aos enfermos mutilados da Africa e Oriente e a algumas atividades editoriais e científicas, as organizações beneficentes privadas do Ocidente necessitam traumatizar emocionalmente todos os doadores potenciais e, para tanto, nada mais adequado que o emprego do aterrorizante pejorativo "lepra". "Apesar dos argumentos apresentados... deve-se considerar a conservação da terminologia corrente relacionada com a lepra, particularmente por causa de seu valor para levantar fundos" escreve um dos membros de poderosa sociedade inglesa, que continua: - "a palavra lepra desperta curiosidade e atenção fornecenđo uma estratégia para conseguir apôio" "Pensamos que quanto mais dinheiro arranjarmos, maior será o impulso dos programas de tratamento e pesquisa". - "Mesmo contra este 'background" de reprovação implícita, temos que continuar confiando na dinâmica de um apelo..." (10). - Qual será o efeito de nova terminologia sobre os filântropos e associações filantrópicas? Pergunta angustiado um outro (1).

Essas associações são poderosas; mantem ou subsidiam generosamente organizações internacionais e periódicos especializados. Elas "têm responsabilidade permanente nesse assunto: com seu passado de competência e dedicação, seus recursos atuais e sua capacidade de iniciativa local, podem elas influir na política e na prática de várias maneiras" (Editorial de "Leprosy Review" sobre "integração") (4). 
Tudo leva a crer, portanto, que os enfermos do Brasil ( 3 a $4 \mathrm{em}$ cada 1.000 habitantes), da América Latina, Estados Unidos, Espanha e Portugal, bem como seus milhões de familiares, deverão continuar sofrendo o injusto e milenar estigma da "lepra" (enquanto perecem as atividades preventivas dessas áreas), a fim de que não pereça a caridade de alguns paises, visando a outros paises. Prevalecerão as superstições e as lendas, bem como as noções falsas de incurabilidade e extrema contagiosidade da moléstia, aterrorizando o público, envergonhando e ostracizando o paciente e assegurando seu ocultamento dos serviços de saude.

\section{As difíceis soluções.}

Diante de tão poderosos obstáculos - a indiferença internacional e o dinheiro - ficou praticamente bloqueado todo e qualquer esforço de indivíduos ou pequenos grupos isolados no sentido de libertar seus paises do "trágico nome lepra" (6) e de esclarecer o público. Ficou explicada, afinal, a antes incompreensivel resistência a uma modificação terminológica, num mundo em que tais modificações são habituais e necessárias em todos os ramos da atividade humana.

Um apelo acaba de ser dirigido às entidades beneficentes de áreas não-endêmicas exortando-as a encontrar meios de continuar sua benemerência visando a certas regióes, sem prejuizo de outras (18). Ainda não houve tempo suficiente para qualquer resposta - mas as perspectivas não são nada favoráveis.

Caberá aos Governos e às associaçóes científicas, médicas ou humanísticas (historiadores, antropólogos, sociólogos e educadores) dos países afetados pelo complexo "lepra-pejorativo e endemia" (16) livrarem-se por iniciativa própria do elemento estigmatizante e pejorativo do "complexo" e, por todas as maneiras, exigirem a atenção das organizações internacionais de que fazem parte e para as quais contribuem.

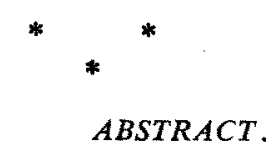

All skin diseases which might have corresponded to the ritual "tsara'ath" of the Hebrew' Old Testament and to its Greek translation "lepra" changed names and are now known as vitiligo, pso- 
riasis, etc.. Curiously, the disease caused by Hansen's bacillus, not described in that religious text and only later known as "lepra", is the only disease which has never been able to get rid of that pejorative and its infamous connotation. This fact does not harm non-endemic countries of biblical tradition, but is the cause of numerous and serious social, human and preventive problems in the endemic countries of the same religious background - the victims of the complex "leprosy-the pejorative, the endemic", of which Latin America is the major sufferer, especially Brazil.

The liberation from this vilifying term is being hampered by 1). - the name given to Hansen's bacillus ("Mycobacterium leprae") - 2). - the lack of interest of the influential minority of biblical tradition which inherited the pejorative term but not the disease, and - 3). - the interest of the powerful voluntary agencies of non-endemic areas, who need the emotion loaded pejorative "leprosy" to arouse the European and North-American public and induce them to offer donations.

It is up to the governments and scientific associations of doctors, public health officials, sociologists, historians, anthropologists and educators of the endemic countries to get rid of that pejorative and to demand help from the international organs to which they belong and to which they contribute.

BIBLIOGRAFIA .

1. - COCHRANE, R. G. - "In defense of the name leprosy"; International J. Leprosy (38: 207-209, Correspondence), 1970.

2. - GASPAR, A. P. A. \& GASPAR, N. K. - Nômina Dermatológica; Rio de Janeiro, s. c. p., 451 p., 1972.

3. - GRAMBERG, K. P. C. A. - "Leprosy" and the Bible"; The Bible Translator 11 (1), 1960.

4. - 'INTEGRATION' - present prospects; Leprosy Review/Editorial (42: 235-236), 1971.

5. - JEANSELME, Ed. - La Lèpre; G. Doin, Paris, pp. 12-16, 1934.

6. - LENDRUM, F. C. - The tragic name of "leprosy"; Modern Hosp. (64: 79-80), 1945.

7. - LESER, W. - Norma Técnica SS-3/70: Terminologia referente à Hanseníase'; Diário Oficial do Estado de São Paulo de 11 de dezembro de 1970.

8. - LETAYF, S. - Recherche sur la mentalité des malades de la lèpre; Rev. Psicol. Norm. Patol. (1: 3-59) 1965. 
9. - LIE H. P. - On Leprosy in the Bible; Acta Dermato-Venereologica (I8: 524-545), 1937.

10. - MANGiATERRA, M. - "Terapia Semantica" en la educación sanitária antihanseniana. "Semantic Therapy" in antihansenic health education; Neol. Hansen. (4: 15-20), 1970.

11. - Nomes Novos acompanham o Progresso mas o Antiquado, Degradante e Perigoso Termo "Lepra" ainda está por aí. Apele!; 'O Neologismo Hanseníase' - 'The Neologism Hanseniasis' (4: 39-56), 1972.

12. - PEARSON, E. A. - Leprosy or Hansen's disease: a study of semantic conflict; Presented at the Annual Commissioned Officers Association - Clinical Society of the Public Health Services Meeting; New York, June, 1972 apud Hansen. res. not./abs. news, 5 (1), in printing, 1974.

13. - RABELlo, F. E. - Nomenclatura Dermatológica; Freitas Bastos, 301 p., Rio de Janeiro, 1970.

14. - ROLSTON, R. H. \& CHESTEEN, H. E. - The identification of psychosocial factors related to the rehabilitation of leprosy patients; Baton Rouge, La. School Soc. Welfare, Louisiana State Univ., 1970.

15. - ROTBERG, A. - "Hanseniasis", the new official name for Leprosy in São Paulo, Brazil.; Derm. Int. (8 (1): 40-43), 1969.

16. - ROTBERG, A. - The serious Latin-American problems caused by the complex: "Leprosy: the word, the disease" and an appeal for world co-operation'; Leprosy Rev. (43: 96-105), 1972.

17. - ROTBERG, A. - 'O preço exorbitante e proibitivo das sulfonas: degradação social e colapso econômico' / 'The exhorbitant and prohibitive price of sulfones: social degradation and economic collapse'.; Hansen. res. not. abs./news (3: 295-302), 1972.

18. - ROTBERG, A. - Notas sobre motivo financeiro para conservar o nome "Lepra": Angariação de donativos na Europa não endêmica, para a pesquisa e para o bem-estar de pacientes na Africa e Oriente (Nocivo para o Ocidente); The Neologism Hanseniasis (6 (2) 35-43), idem em Português, Secretaria de Estado da Saúde CST/T-S, Divisão de Hansenologia e Dermatologia Sanitária, 1974.

19. - SKINSNES, O. K. - 'Letter to the editor'; Leprosy Review (44: 94-95), 1973.

20. - STRINGER, T. A. - 'Leprosy and a "disease called leprosy"'; Leprosy Review (44: 70-74), 1973.

21. - TAS, J. - On the leprosy in the Bible; 7ème Congrès International d'Histoire des Sciences, Annales, pp. 583-587, Jerusalém, 1953. 